\title{
EQUAÇÕES VOLUMÉTRICAS PARA O CERRADO SENSU STRICTO, EM MINAS GERAIS
}

\author{
Ana Luiza Rufini ${ }^{1}$, José Roberto Soares Scolforo², Antonio Donizette de Oliveira², José Márcio de Mello²
}

(recebido: 18 de março de 2009; aceito: 30 de outubro de 2009)

RESUMO: Neste trabalho, a fisionomia Cerrado Sensu Stricto presente em três regiões da bacia do rio São Francisco, no estado de Minas Gerais, foi estudada com os seguintes objetivos: ajustar e selecionar equações para estimar o volume total e o volume de fuste; testar a similaridade entre modelos volumétricos; mostrar o comportamento do volume do fuste e galhos da árvore e avaliar a porcentagem de casca por classe diamétrica. Para isso, realizou-se a cubagem rigorosa pelo método de Huber, onde a base de dados foi composta de 497 árvores, distribuídas em seis classes de diâmetro, dentro das regiões de estudo. Mensurou-se a espessura de casca nas alturas de $0 \%, 25 \%, 50 \%, 75 \%$ e 100\% da altura comercial. A acurácia dos modelos foi avaliada pelo coeficiente de determinação, erro padrão residual e análise gráfica dos resíduos. Para testar a identidade de modelos, utilizou-se o método desenvolvido por Graybill (1976). Os modelos selecionados para todas as variáveis testadas foram os de Schumacher e Hall e de Spurr logaritmizados. De acordo com o teste de identidade de modelos, para todas as variáveis analisadas, existe similaridade entre as regiões 2 e 3 . Em relação ao comportamento do volume, observou-se que as menores classes diamétricas possuem maior volume de fuste do que de galhos e também que existe tendência de decréscimo da porcentagem de casca com o aumento da classe diamétrica, para as três regiões estudadas.

Palavras-chave: Volumetria, similaridade de modelos, porcentagem de casca.

\section{VOLUME EQUATIONS FOR THE SAVANNAH (CERRADO), IN MINAS GERAIS STATE}

\begin{abstract}
In this work, the physiognomy Savannah (Cerrado), present in three regions of the São Francisco River Basin, in Minas Gerais State, was studied with the following objectives: to adjust and to select equations to estimate total volume and stem volume; to test the similarity among volumetric models; to show the behavior of the volume in the stem and branches of the tree, and to evaluate the bark percentage in each diametric class. For this, the rigorous scaling using the method of Huber was accomplished, in which the data base was composed by 497 trees, distributed in six diameter classes, inside the three study areas. The bark thickness at the heights of 0\%, 25\%, 50\%, 75\% and 100\% of the commercial height was measured. The accuracy of the models was evaluated by the determination coefficient, standard error of estimate and graphic analysis of the residuals. To test model identity, the method used was the one developed by Graybill (1976). The models selected for all the tested variables were the ones of Schumacher and Hall and of Spurr, transformed in logarithm. According to the identity test of models, for all the tested variables, similarity exists among the areas 2 and 3. Regarding to the behavior of volume, it was observed that the smallest diametric classes possess larger stem volume than the branches and that there is also a tendency of decreasing the bark percentage with the increase of the diametric class for the three studied areas.
\end{abstract}

Key-words: Volumetry, models similarity, bark percentage.

\section{INTRODUÇÃO}

O Cerrado é o bioma de maior expressão no estado de Minas Gerais, sendo o Cerrado Sensu Stricto o seu tipo fisionômico predominante. Entretanto, este é um dos ambientes mais ameaçados do mundo. No estado de Minas Gerais, o Cerrado tem sofrido forte pressão em razão das severas intervenções antrópicas relacionadas à expansão urbana e agropecuária, à infra-estrutura e à produção mineral.

Conhecer o potencial volumétrico e a flora dessa fisionomia é de extrema importância no estabelecimento de planos de manejo, visando à conservação ou preservação do bioma Cerrado. Para tanto, é importante implementar sistema de amostragem, destacando aqui, a qualidade das estimativas volumétricas, por meio de equações, para que se possa obter informações fidedignas para balizamento dos planos de manejo (FAO, 1973; SCOLFORO \& MELLO, 2006).

Nesse contexto, os volumes total, comercial ou de partes da árvore são variáveis de grande interesse a serem estimadas em florestas sujeitas à prática do manejo florestal sustentável. Estimando-se estes volumes com precisão, os planos de manejo, as análises de investimento e as tomadas de decisão também serão precisos.

${ }^{1}$ Engenheira Florestal, Doutoranda em Engenharia Florestal - Departamento de Ciências Florestais - Universidade Federal de Lavras Cx. P. 3037 - 37200-000 - Lavras, MG - alrufini@dcf.ufla.br

${ }^{2}$ Engenheiro Florestal, Professor Dr. do Departamento de Ciências Florestais - Universidade Federal de Lavras - Cx. P. 3037 - $37200-000$ Lavras, MG - jscolforo@dcf.ufla.br, donizete@dcf.ufla.br, josemarcio@dcf.ufla.br

Cerne, Lavras, v. 16, n. 1, p. 1-11, jan./mar. 2010 
Dentre os estudos relacionados com a estimativa volumétrica da vegetação do Cerrado, pode-se citar Scolforo et al. (1993), para o Cerrado Sensu Stricto no Vale do Jequitinhonha em Minas Gerais, e Centro Tecnológico de Minas Gerais - CETEC (1995) para diferentes fisionomias do estado de Minas Gerais.

Scolforo et al. (1993) concluíram que para a estimativa do volume do fuste e do volume total o modelo não linear de Schumacher e Hall foi o de melhor desempenho. CETEC (1995) também selecionou o modelo não linear de Schumacher e Hall como o mais preciso, em todos os casos de volume e tipologia estudados.

Entretanto, outros autores como Scolforo et al. (2004), estimando o volume para a Candeia (Eremanthus erythropappus) no município de Aiuruoca, selecionaram o modelo logaritmizado de Schumacher e Hall como o mais preciso para esta estimativa. Camolesi (2007) comparou e selecionou modelos de equações de volume para essa mesma espécie, em três municípios do estado de Minas Gerais e concluiu que o modelo de Spurr logaritmizado foi o que proporcionou melhores estimativas.

Mediante o exposto, conduziu-se o presente trabalho, com os objetivos de selecionar equações volumétricas para três regiões de Cerrado Sensu Stricto na bacia do rio São Francisco; testar a similaridade entre modelos (identidade, forma e nível) para a variável volume, nas três regiões de estudo; mostrar o comportamento do volume distribuído no fuste e copa até galhos com $3 \mathrm{~cm}$ de diâmetro, distribuídos em diferentes classes diamétricas; e avaliar a porcentagem de casca por classe diamétrica.

\section{MATERIAL E MÉTODOS}

\subsection{Região de estudo}

A bacia do rio São Francisco, um rio brasileiro, possui área de $631.133 \mathrm{~km}^{2}$, o que corresponde a 7,4\% do território brasileiro, sendo um rio exclusivo do território brasileiro. No estado de Minas Gerais, a bacia apresenta características climáticas e geográficas bastante variadas. A precipitação média anual varia de 800 a $1.500 \mathrm{~mm}$, com chuvas predominantes nos meses de novembro a abril, e temperatura média anual entre 18 a $27^{\circ} \mathrm{C}$. Da cabeceira do rio até o município de Pirapora, o clima predominante é o tropical úmido; depois de Pirapora, prevalece o clima tropical semiárido (SFRANCISCO, 2008).

Para a realização deste estudo, a bacia do rio São Francisco, no estado de Minas Gerais, foi dividida em 3 regiões, conforme Figura 1. A região 1 compreende as sub- bacias $1,2,3$ e 4 do rio São Francisco; a região 2 compreende as sub-bacias 5,6 e 10, e a região 3 compreende as sub-bacias 7,8 e 9 .

\subsection{Base de dados}

Foram cubadas 497 árvores encontradas na fisionomia Cerrado Sensu Stricto, distribuídas em oito classes de diâmetro e em cada região descrita anteriormente, sendo 157 árvores para a região 1; 113 árvores para a região 2; e 227 árvores para a região 3 . As cubagens foram realizadas em áreas com processos de desmate já autorizados pelo Instituto Estadual de Florestas do Estado de Minas Gerais (IEF) (desmatamentos para fins agropecuários e ou planos de manejo sustentado).

$\mathrm{O}$ número de árvores cubadas em cada região foi proporcional à densidade relativa das espécies, fato este viabilizado para as quatro espécies que apresentaram maior densidade relativa. As demais, que apresentavam baixos valores de densidade relativa, foram agrupadas como se tratasse de uma miscelânea de espécies e sua densidade básica computada como se fosse uma única espécie. Assim, para cada região, definiu-se o número mínimo de 80 árvores cubadas (10 árvores por classe diamétrica), sendo esse número proporcionalizado com o valor da densidade relativa das quatro espécies mais densas. A partir daí, obteve-se o número de árvores dessas espécies a serem cubadas, o qual foi distribuído nas diferentes classes diamétricas. A este foi agregado o número de árvores das demais espécies (miscelânea) para compor a base de ajuste dos modelos volumétricos. Como, para a miscelânea, há maior variação de fuste, copa e forma, foram proporcionalmente cubadas mais árvores que a prescrição matemática indicou.

Antes de proceder à cubagem rigorosa, mensurouse a circunferência a 1,30 metros de altura (Cap), a altura total e a altura do fuste da árvore selecionada. Depois, esta árvore foi georreferenciada, abatida, e teve medida a circunferência do toco (altura $\leq 10 \mathrm{~cm}$ ) em centímetro na sua extremidade superior e a altura do toco.

Todos os galhos da árvore cubada que eram menores que $3 \mathrm{~cm}$ de diâmetro foram retirados e, então, mediu-se a altura comercial. Depois, a árvore foi cubada medindo-se a circunferência intermediária nas alturas de 0,30 m, 0,70 m, 1,00 m, 1,30 m e 2,00 m e, a partir daí, de metro em metro, até o fim do fuste. Para a cubagem dos galhos, face à irregularidade na forma dos mesmos, adotaram-se comprimentos de seções diferentes, que poderiam ter 10 $\mathrm{cm}$ ou 1,6 m, e tomou-se a circunferência no meio dessas. 


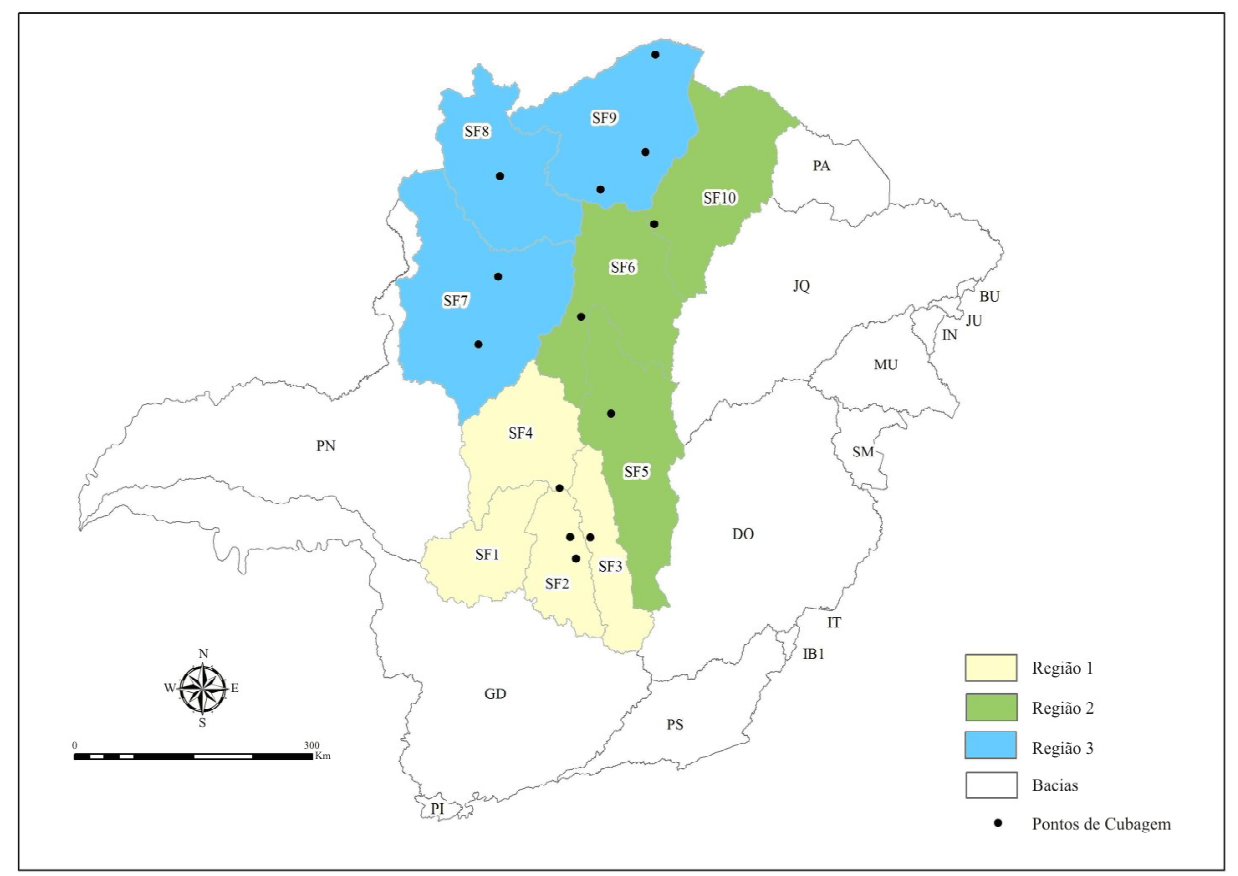

Figura 1 - Mapa do estado de Minas Gerais, destacando-se as três regiões de estudo presentes dentro da bacia do rio São Francisco.

Figure 1 - Map of the Minas Gerais State, being distinguished the three regions of study in São Francisco River basin.

Para quantificar o volume real de cada seção da árvore cubada, utilizou-se a fórmula de Huber, conforme Scolforo et al. (2004) e Machado \& Figueiredo Filho (2006).

A espessura de casca também foi mensurada utilizando uma régua graduada em milímetros.

\subsection{Modelos para estimativas volumétricas}

Foram ajustados 12 modelos que tinham como variáveis independentes o diâmetro medido a 1,30 m de altura e a altura total da árvore, e como variáveis dependentes, o volume total e de fuste, ambos com e sem casca, conforme Scolforo (2005).

$\mathrm{O}$ critério de seleção dos modelos baseou-se no coeficiente de determinação ajustado, no erro padrão residual corrigido e em porcentagem e na análise gráfica de resíduos, além de identificar a existência ou não de multicolinearidade.

$\mathrm{O}$ coeficiente de determinação $\left(\mathrm{R}^{2}\right)$ expressa a quantidade de variação da variável dependente que é explicada pelas variáveis independentes. Assim, quanto mais próximo de um for o valor do $\mathrm{R}^{2}$, melhor terá sido o ajuste.
O erro padrão residual (Syx) mede a dispersão média entre os valores observados e estimados ao longo da linha de regressão. Menores valores dessa estatística indicam melhores ajustes. Nos modelos em que a característica de interesse ou variável dependente sofre transformação, foi necessário retransformar o erro padrão residual.

Essas duas estatísticas, coeficiente de determinação e erro padrão residual, não foram utilizadas isoladamente para o julgamento da precisão do modelo, pois podem fornecer informações distorcidas sobre o ajuste. $\mathrm{O}$ recomendado é complementá-la por meio da análise gráfica de resíduos, que é decisiva na avaliação da qualidade do modelo, pois permite detectar se há ou não tendenciosidade na estimativa da variável dependente ao longo de toda a linha de regressão.

\subsection{Teste de identidade de modelos}

O teste de identidade entre modelos foi realizado com o propósito de avaliar a possibilidade de uma única equação modelar o comportamento das variáveis volume total e volume de fuste, com e sem casca, nas três regiões estudadas. Para cada variável, foram testadas todas as

Cerne, Lavras, v. 16, n. 1, p. 1-11, jan./mar. 2010 
combinações que representam as várias possibilidades de agrupamento entre as três regiões.

Para verificar a possibilidade de identidade entre modelos, foi utilizado o teste de identidade descrito por Graybill (1976), baseado no teste de F, a partir da redução da soma de quadrados. Essa técnica também foi utilizada por Regazzi (1992) e Scolforo (2005).

$\mathrm{O}$ teste estatístico baseou-se na diferença entre o total das somas dos quadrados das regressões ajustadas para cada região isoladamente (modelo completo) e a soma dos quadrados da regressão ajustada para uma única base de dados contendo todas as informações das três regiões de estudo (modelo reduzido). A hipótese de nulidade testada foi a de que os parâmetros eram iguais, ou seja, que o vetor dos parâmetros de um modelo fosse igual ao outro comparado. A rejeição dessa hipótese implicou na impossibilidade do uso de um modelo único com os parâmetros comuns.

\section{RESULTADOS E DISCUSSÃO}

\subsection{Seleção de equações volumétricas}

Analisando-se as medidas de precisão $\mathrm{R}^{2}$, Syx e análise gráfica dos resíduos para as variáveis dependentes volume total e volume de fuste, ambos com e sem casca, em cada uma das três regiões, observou-se que os modelos de Schumacher e Hall e de Spurr, em suas formas logaritmizadas, se apresentaram melhor do que os demais modelos.

Conforme pode ser observado, por meio da Tabela 1, o modelo de Schumacher e Hall logaritmizado foi o que apresentou os maiores valores de $\mathrm{R}^{2}$ nas três regiões. Já o modelo de Spurr logaritmizado, mesmo não tendo o maior valor de $\mathrm{R}^{2}$, se apresentou com valores bem próximos a este. Quanto ao erro padrão residual (Syx) $\mathrm{em} \mathrm{m}^{3} \mathrm{e}$ porcentagem, observa-se para os dois modelos, que este é mais elevado que o de plantações, fato que decorre da variabilidade de uma amostra típica das árvores nativas, em particular do Cerrado, onde a variação das copas é muito grande. Entretanto, eles apresentaram resíduos bem distribuídos por classe de diâmetro e praticamente sem tendenciosidade. Esse fato garante ótimas estimativas do volume, já que a média dos erros ( $\overline{\mathrm{E}}$ ) da estimativa tende a se anular, em função da ótima distribuição dos resíduos no espectro avaliado das variáveis independentes.

Os valores de coeficiente de determinação encontrados para os modelos de Schumacher e Hall e de Spurr, em suas formas logarítmicas $\left(\mathrm{R}^{2}>96 \%\right)$, foram coerentes aos encontrados por CETEC (1995) que, ao determinar equações volumétricas para florestas nativas de Minas Gerais, encontrou, para a fisionomia Cerrado, valores de $\mathrm{R}^{2}$ próximos a $96 \%$ para a variável volume total com casca, para estes mesmos modelos.

Scolforo et al. (1993) selecionaram equações de volume para o Cerrado Sensu Stricto na bacia do rio Jequitinhonha e encontraram valores de $\mathrm{R}^{2}$ próximos a $99 \%$ para o modelo de Schumacher e Hall não linear, com valores aceitáveis de erro padrão residual e com distribuição de resíduos sem qualquer tendenciosidade.

Pelos resultados do presente estudo, os modelos de Schumacher e Hall e de Spurr em suas formas logarítmicas, devem ser utilizados para a estimativa de volume individual em áreas de Cerrado na bacia do rio São Francisco, com as equações apresentadas na Tabela 1, em razão do bom desempenho do $\mathrm{R}^{2}$, Syx e da distribuição gráfica dos resíduos.

\subsection{Teste de identidade de modelos}

As equações volumétricas, específicas para cada uma das três regiões da bacia do rio São Francisco estudadas neste trabalho, oriundas do modelo de Schumacher e Hall logarítmico, foram submetidas ao teste de identidade de modelos segundo a região e para cada variável volumétrica analisada no item anterior. $\mathrm{O}$ teste de identidade foi realizado segundo o método proposto por Graybill (1976).

Conforme se observa na Tabela 2 , houve similaridade no comportamento de todas as variáveis analisadas, para as regiões 2 (SF 5, 6 e 10) e 3 (SF 7, 8 e 9). Para as regiões em que foi observada identidade, os dados da cubagem rigorosa foram agrupados, e novas equações foram ajustadas. Sendo assim, podem ser utilizadas as mesmas equações de Schumacher e Hall logarítmica que estimem volume total e volume de fuste, com e sem casca, nas regiões 2 e 3 , e outras para estimar estas mesmas variáveis na região 1 .

Se não houver interesse em utilizar essa opção, basta usar as equações apresentadas na seção anterior para volume com casca e para volume sem casca.

\subsection{Comportamento da variável volume}

Na Figura 2, é apresentado o comportamento do volume do fuste e do volume dos galhos, ambos em porcentagem, por classe de diâmetro, para as três regiões de estudo. Pode-se observar, por meio desta, que nas três regiões da bacia do rio São Francisco há tendência de maior volume de fuste e menor volume de galhos nas árvores que possuem menor diâmetro, e a partir de 


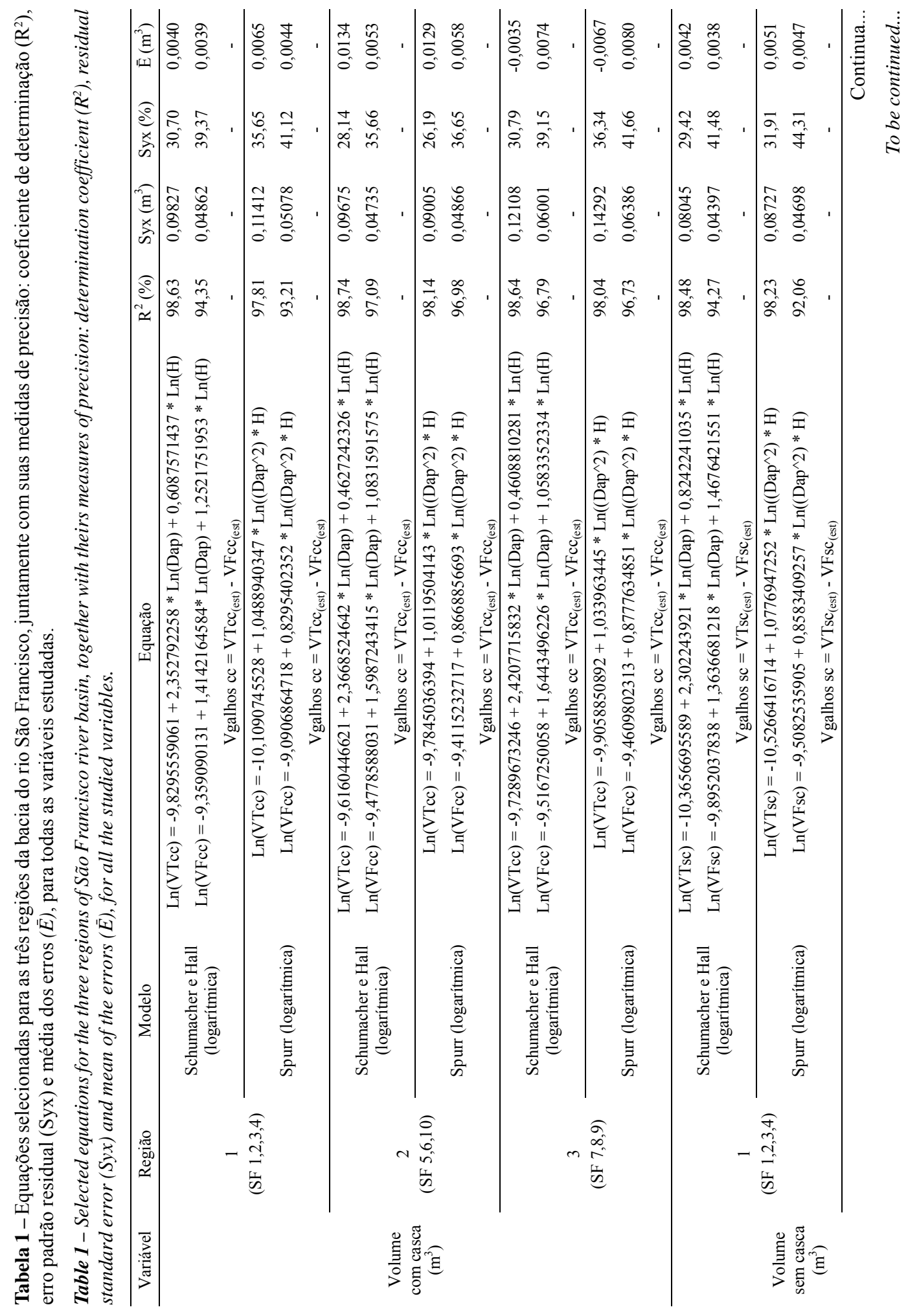




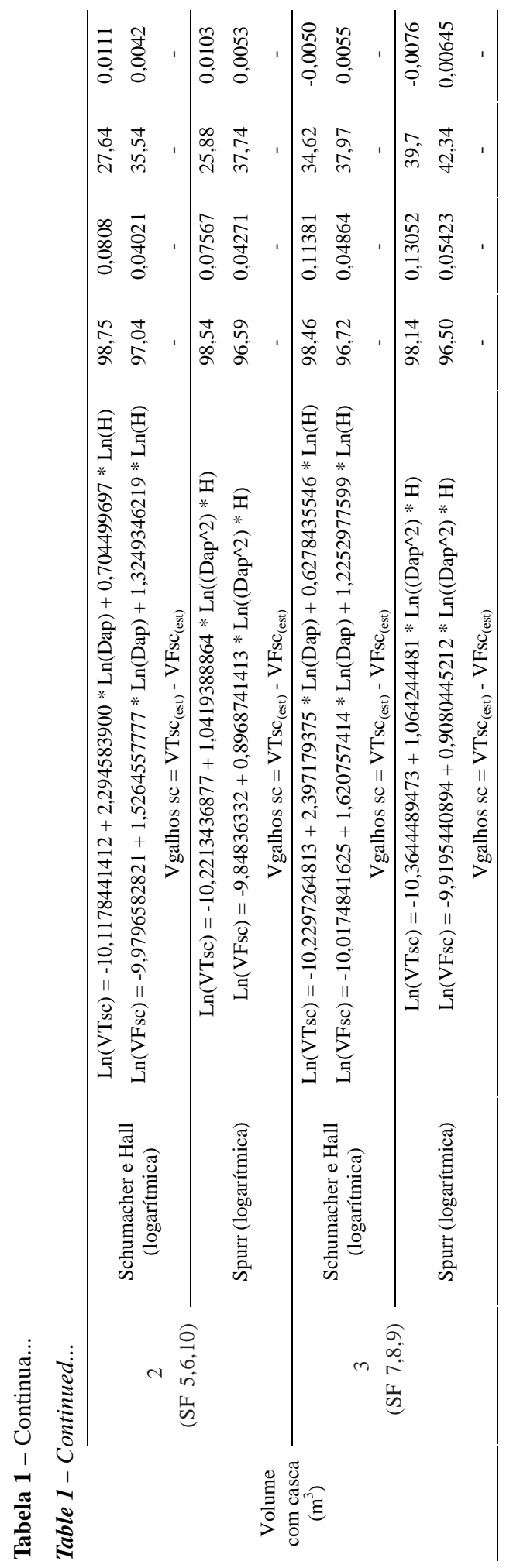

Cerne, Lavras, v. 16, n. 1, p. 1-11, jan./mar. 2010 


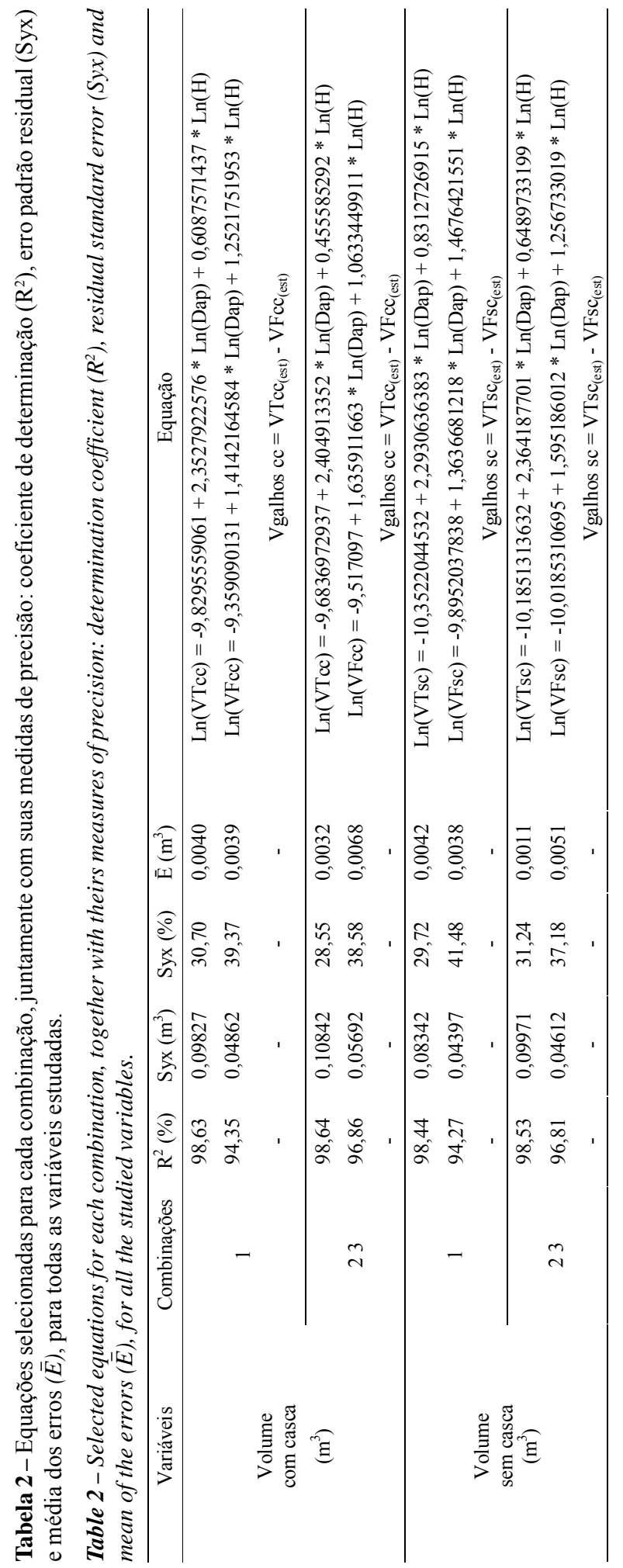




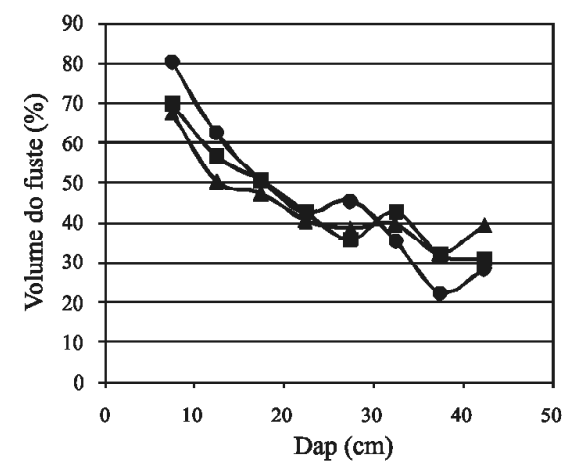

(a)

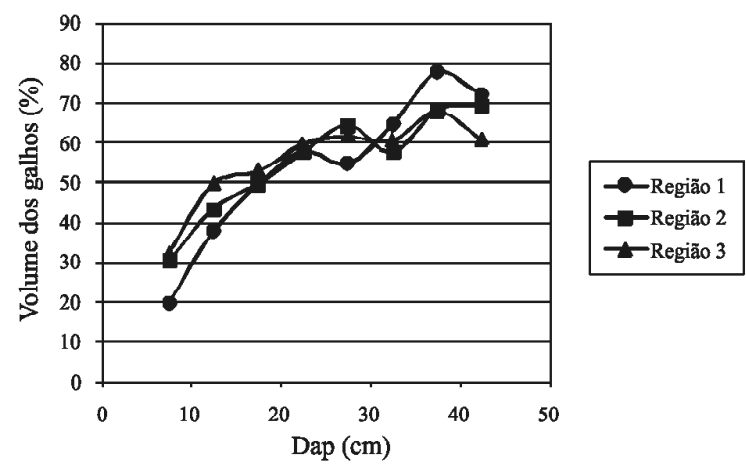

(b)

Figura 2 - Comportamento da porcentagem de volume no fuste (a) e nos galhos (b) para as três regiões de estudo da bacia do rio São Francisco.

Figure 2 - Behavior of the percentage of volume in the stem (a) and in the branches (b) for the three regions of study of the São Francisco river basin.

$10-15 \mathrm{~cm}$, essa relação se inverte, passando a apresentar maior volume de galhos e menor volume de fuste.

Nota-se, ainda, nesta Figura, que as regiões 2 e 3 apresentam comportamento semelhante, afirmando o que foi mostrado pelo teste de identidade de modelos, que apontou similaridade nessas duas regiões quanto ao comportamento do volume.

Os valores médios de volume foram iguais a $54,91 \%$ no fuste e 45,09\% nos galhos da região 1, 51,27\% no fuste e $48,73 \%$ nos galhos da região 2 e, $48,31 \%$ no fuste e $51,69 \%$ nos galhos da região 3 .

Felfili (1983) realizou a cubagem rigorosa da copa de árvores de florestas nativas no norte do estado do Mato Grosso e concluiu que o volume de galhos representa cerca de $30 \%$ do volume total daquelas florestas. Campos et al. (1992), estudando o volume de Eucalyptus saligna em Viçosa, MG, concluíram que o volume médio de madeira da copa em relação ao volume total das árvores foi de 35,5\%.

Os valores de volume de galhos encontrados por estes autores são inferiores aos encontrados neste estudo, em razão do fato de as árvores presentes na fisionomia Cerrado Sensu Stricto, normalmente, crescerem mais espaçadas umas das outras, fazendo com que a proporção do volume contido na copa aumente à medida que as árvores ficam maiores. De maneira diferente, as árvores plantadas ou de mata, que são mais próximas, possuem, assim, menor quantidade de galhos.

\subsection{Porcentagem de casca}

Na Figura 3, mostra-se o comportamento da porcentagem de casca no fuste e nos galhos, por classe diamétrica, para as três regiões de estudo. Por meio desta, pode-se observar que, para as três regiões de estudo, existe tendência de as menores classes possuírem maior porcentagem de casca em relação às classes diamétricas maiores. Isso ocorre tanto para volume de fuste quanto para volume de galhos, com variações entre $25 \%$ e $10 \%$ das menores para as maiores classes diamétricas. Camolesi (2007), quantificando o volume por classe de diâmetro da espécie Eremanthus erythropappus (Candeia), em três municípios de Minas Gerais, encontrou esta mesma tendência para porcentagem de casca nos três municípios estudados, com valores variando entre $25 \%$ e $8 \%$.

A porcentagem média de casca no fuste e nos galhos foi respectivamente para a região 1 igual a $14,58 \%$ e $16,44 \%$, para a região $2,15,91 \%$ e $16,95 \%$, e para a região 3 , igual a $17,96 \%$ e $18,29 \%$. E de maneira geral, o cerrado apresentou $16,15 \%$ de casca no fuste e $17,23 \%$ de casca nos galhos.

\subsection{Intensidade amostral}

$\mathrm{Na}$ Tabela 3, apresenta-se a intensidade amostral referente ao número de árvores cubadas, por classe diamétrica para cada uma das três regiões estudadas, considerando um erro igual a $15 \%$.

Como pode ser observado nessa tabela, em todas as classes diamétricas das três regiões estudadas, o número de árvores cubadas foi suficiente, sendo que para a maioria das classes, esse valor foi muito superior ao que a intensidade amostral prescreveu, mostrando que a cubagem realizada foi suficiente para um erro de $15 \%$. 


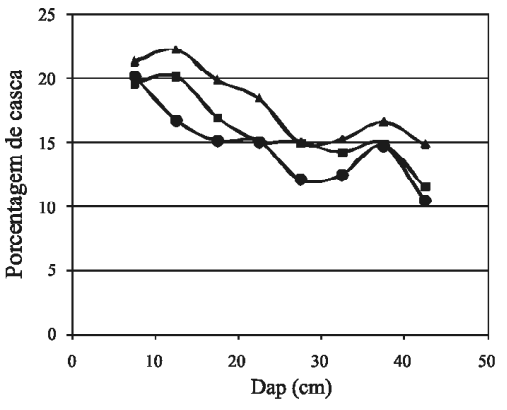

(a)

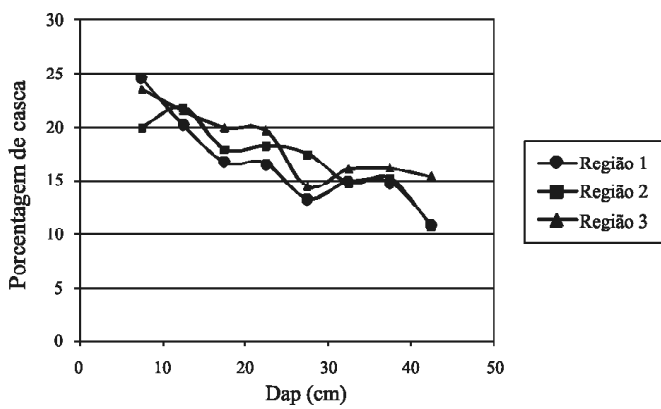

(b)

Figura 3 - Comportamento da porcentagem de casca no fuste (a) e nos galhos (b) por classe de diâmetro, para as três regiões de estudo situadas na bacia do rio São Francisco.

Figure 3 -Behavior of the percentage of bark in the stem (a) and the branches $(b)$ for diametric class, for the three regions of study situated in São Francisco river basin.

Tabela 3 - Número de árvores prescrito para ser amostrada, de acordo com a intensidade amostral (IA), por classe de diâmetro.

Table 3 - Number of prescribed trees to be sampled, in accordance with the amostral intensity (IA), by diametric class.

\begin{tabular}{|c|c|c|c|c|c|c|}
\hline Região & CLD & Desvio médio & $\mathrm{V}$ médio & $\mathrm{n}$ & $\mathrm{CV}(\%)$ & IA \\
\hline \multirow{9}{*}{1} & $5-10$ & 0,0109 & 0,02171 & 35 & 60,34 & 35,10 \\
\hline & $10-15$ & 0,0328 & 0,08587 & 35 & 41,29 & 17,33 \\
\hline & $15-20$ & 0,0658 & 0,18906 & 36 & 38,15 & 15,00 \\
\hline & $20-25$ & 0,0846 & 0,36344 & 17 & 23,26 & 6,95 \\
\hline & $25-30$ & 0,0988 & 0,59319 & 13 & 40,51 & 16,79 \\
\hline & $30-35$ & 0,2694 & 0,89576 & 11 & 30,08 & 9,96 \\
\hline & $35-40$ & 0,4392 & 1,46758 & 7 & 46,64 & 21,66 \\
\hline & $>40$ & 0,2530 & 2,00906 & 3 & 12,59 & 1,69 \\
\hline & Média & 0,4419 & 0,70321 & - & - & - \\
\hline \multirow{9}{*}{2} & $5-10$ & 0,0079 & 0,01796 & 27 & 44,14 & 19,58 \\
\hline & $10-15$ & 0,0175 & 0,05095 & 19 & 40,44 & 16,73 \\
\hline & $15-20$ & 0,0495 & 0,15723 & 20 & 31,48 & 10,91 \\
\hline & $20-25$ & 0,0728 & 0,28489 & 13 & 25,56 & 7,91 \\
\hline & $25-30$ & 0,1392 & 0,49019 & 10 & 28,41 & 9,09 \\
\hline & $30-35$ & 0,2932 & 0,87855 & 11 & 33,37 & 11,85 \\
\hline & $35-40$ & 0,3010 & 1,19222 & 7 & 25,25 & 7,71 \\
\hline & $>40$ & 0,4549 & 1,70120 & 6 & 55,64 & 30,08 \\
\hline & Média & 0,4617 & 0,59665 & - & - & - \\
\hline
\end{tabular}

Continua...

To be continued... 
Tabela 3 - Continua...

Table 3 - Continued...

\begin{tabular}{ccccccc}
\hline Região & CLD & Desvio médio & V médio & $\mathrm{n}$ & CV $(\%)$ & IA \\
\hline & $5-10$ & 0,0082 & 0,01809 & 52 & 48,96 & 23,70 \\
& $10-15$ & 0,0281 & 0,06611 & 38 & 42,64 & 18,37 \\
& $15-20$ & 0,0510 & 0,16256 & 34 & 30,06 & 9,94 \\
3 & $20-25$ & 0,0831 & 0,29837 & 35 & 24,44 & 7,23 \\
& $25-30$ & 0,1395 & 0,54803 & 23 & 27,22 & 8,61 \\
& $30-35$ & 0,2794 & 0,86219 & 18 & 32,21 & 11,21 \\
& $35-40$ & 0,2304 & 1,28549 & 14 & 18,55 & 4,84 \\
& $>40$ & 0,5040 & 2,82645 & 13 & 17,83 & 4,47 \\
\cline { 2 - 6 } & Média & 0,5041 & 0,75841 & - & - & -
\end{tabular}

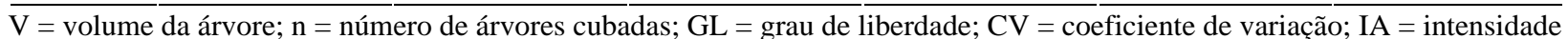
amostral.

A exceção ocorreu apenas na classe diamétrica de $30-35 \mathrm{~cm}$ para a região 1 e maior que $40 \mathrm{~cm}$ para a região 2 , onde a intensidade amostral prescreveu um número de árvores que deveria ter sido amostrada maior do que o número de árvores cubadas.

Pode-se observar ainda nessa tabela que um maior número de árvores deve ser cubado nas menores classes diamétricas em razão da maior variação existente nestas. $\mathrm{O}$ desvio padrão médio e o volume médio para a região 1 (SF $1,2,3$ e 4) foram iguais a 0,4419 e $0,70321 \mathrm{~m}^{3}$, respectivamente, já para a região 2 (SF 5, 6 e 10) foram respectivamente, 0,4517 e $0,59665 \mathrm{~m}^{3}$, e para a região 3 (SF 7,8 e 9), foram 0,5041 e $0,75841 \mathrm{~m}^{3}$, respectivamente.

\section{CONCLUSÕES}

Os modelos de Schumacher e Hall e de Spurr, em suas formas logaritmizadas, foram os mais precisos para estimar as variáveis volume total com e sem casca e volume de fuste com e sem casca, nas três regiões de estudo.

Os volumes total com e sem casca, e volumes de fuste com e sem casca, são similares entre duas regiões da bacia do rio São Francisco, a região 2, que compreende as sub-bacias 5,6 e 10 e a região 3 , que compreende as subbacias 7,8 e 9 .

\section{REFERÊNCIAS BIBLIOGRÁFICAS}

CAMOLESI, J. F. Volumetria e teor alfa-bisabolol para candeia Eremanthus erythropappus. 2007. 101 p. Dissertação (Mestrado em Ciências Florestais) - Universidade Federal de Lavras, Lavras, 2007.

Cerne, Lavras, v. 16, n. 1, p. 1-11, jan./mar. 2010
CAMPOS, J. C. C.; SILVA, J. A.; VITAL, B. R. Volume e biomassa do tronco e da copa de eucaliptos de grande porte. Revista Árvore, Viçosa, v. 16, n. 3, p. 319-336, 1992.

CENTRO TECNOLÓGICO DE MINAS GERAIS. Determinação de equações volumétricas aplicáveis ao manejo sustentado de florestas nativas no estado de Minas Gerais e outras regiões do país: relatório final. Belo Horizonte, 1995.

FELFILI, J. M. Avaliação do potencial florestal e dos resíduos de exploração das florestas do norte do Estado do Mato Grosso. 1983. 70 p. Dissertação (Mestrado em Ciência Florestal) - Universidade Federal de Viçosa, Viçosa, 1983.

FOOD AND AGRICULTURAL ORGANIZATION OF THE UNITED NATIONS. Manual of forest inventory, with special reference to mixed tropical forest. Roma, 1973. 200 p.

GRAYBILL, F. A. Theory and application of linear model. Belmont: Duxbury, 1976. 704 p.

MACHADO, S. A.; FUGUEIREDO FILHO, A. Dendrometria. 2. ed. Guarapuava: Unicentro, 2006. 316 p.

REGAZZI, A. J. Teste para verificar a identidade de modelos de regressão e a igualdade de alguns parâmetros num modelo polinomial ortogonal. Revista Ceres, Viçosa, v. 40, n. 228, p. 176-195, 1992. 
SCOLFORO, J. R. S. Biometria florestal: parte I: modelos de regressão linear e não-linear: parte II: modelos para relação hipsométrica, volume, afilamento e peso de matéria seca. Lavras: UFLA/FAEPE, 2005. 352 p. (Textos Acadêmicos).

SCOLFORO, J. R. S.; LIMA, J. T.; SILVA, S. T. da. Equações de biomassa e volume para Cerrado Sensu Stricto. In: CONGRESSO FLORESTAL BRASILEIRO, 7.; CONGRESSO FLORESTAL PANAMERICANO, 2., 1993, Curitiba. Anais... Curitiba, 1993. p. 508-510.
SCOLFORO, J. R. S.; MELLO, J. M. Inventário florestal. Lavras: UFLA/FAEPE, 2006. 561 p. (Textos Acadêmicos).

SCOLFORO, J. R. S.; PÉREZ, J. F. M.; MELLO, J. M.; OLIVEIRA, A. D. de; CAMOLESI, J. F.; BORGES, F. R.; ACERBI JÚNIOR, F. W. Estimativas de volume, peso seco, peso de óleo e quantidade de moirões para Candeia (Eremanthus erythropappus (DC.) MacLeish). Revista Cerne, Lavras, v. 10, n. 1, p. 87-102, 2004.

SFRANCISCO. Disponível em: 〈http://Www.sfrancisco.bio.bry'. Acesso em: 20 fev. 2008. 